\title{
Reninoma coexisting with adrenal adenoma during pregnancy: A case report
}

\author{
MEI XUE ${ }^{1}$, YAN CHEN $^{1}$, JIN ZHANG $^{1}$, YOUYAN GUAN $^{2}$, LIN YANG $^{3}$ and BING WU \\ Departments of ${ }^{1}$ Diagnostic Radiology, ${ }^{2}$ Urology and ${ }^{3}$ Pathology, \\ Cancer Institute and Hospital, Chinese Academy of Medical Sciences, Beijing 100021, P.R. China
}

Received April 18, 2016; Accepted December 20, 2016

DOI: $10.3892 / \mathrm{ol} .2017 .5802$

\begin{abstract}
Reninoma is a rare form of secondary hypertension. The present study reported a case of reninoma that coexisted with an adrenal adenoma in a young female with secondary hypertension during pregnancy. The patient, a 31-year-old female exhibiting hypertension for $>1$ year, developed a mass in the right adrenal gland, which was detected by an ultrasound scan in the 33rd gestational week. In addition, a well-defined solid mass on the left kidney was detected by a magnetic resonance imaging scan 1 month subsequent to the termination of the pregnancy. The blood pressure (BP) of the patient did not change subsequent to the laparoscopic right adrenalectomy. The patient subsequently underwent laparoscopic left partial nephrectomy 2 months later. The BP levels demonstrated a significant reduction from $177 / 115$ to $125 / 80 \mathrm{mmHg}$ in the same day postoperatively, and stabilized to be within the normal range. The BP level of the patient remained within the normal range subsequent to a 6-month follow-up. Pathological analysis revealed reninoma on the left kidney. The present study aimed to provide information for radiologists who may encounter this type of benign tumor in the future, which exhibits elevated BP levels.
\end{abstract}

\section{Introduction}

Reninomas, or renal juxtaglomerular cell tumors, develop within the juxtaglomerular apparatus through the evolution of small artery smooth muscle cells. These tumor cells produce

Correspondence to: Dr Yan Chen, Department of Diagnostic Radiology, Cancer Institute and Hospital, Chinese Academy of Medical Sciences, 17 Pan Jia Yuan Nan Li, Chaoyang, Beijing 100021, P.R. China

E-mail:9476138@qq.com

Abbreviations: T2WI,T2 weighted-image; T1WI, T1 weighted-image; PA, primary aldosteronism

Key words: reninoma, juxtaglomerular cell tumor, primary aldosteronism, adrenal adenoma, secondary hypertension excessive amounts of renin that results in severe hypertension with hypokalemia and hyperaldosteronism, through the activity of the renin-angiotensin aldosterone system (1). It is a rare form of secondary hypertension. Removing the reninoma results in the conversion of increased blood pressure to normal blood pressure (2). Therefore, perioperative hemodynamic management is important in patients who undergo surgery for the removal of a reninoma.

Adrenal adenoma is a benign neoplasm, which is derived from cells of the adrenal cortex, and may be functionally active or nonfunctional (3). Functional adrenal adenoma is able to cause aldosteronism or Cushing's syndrome. Primary aldosteronism (PA) is characterized by autonomous aldosterone production, which is a cause of secondary hypertension (4). Evidence has developed over the past decades and led to the recognition that autonomous adrenal aldosterone production, termed primary aldosteronism, is common in hypertensive patients. Between 5 and $13 \%$ of patients with hypertension have primary aldosteronism (5).

The present study reported a rare case of reninoma coexisting with an adrenal adenoma in a young female with secondary hypertension during pregnancy.

\section{Case report}

A 2.5-cm mass was detected on the right adrenal gland of a 31-year-old pregnant female with hypertension in her 33rd gestational week by an ultrasound scan. The patient presented with a personal history of elevated blood pressure (BP) for several months prior to conception, and exhibited a family history of hypertension. There were no other abnormalities found by the ultrasounds of the adrenal gland and the renal artery, therefore the patient was diagnosed with primary hypertension. The BP levels of the patient were uncontrolled during pregnancy. In the $35 \mathrm{th}+6$ gestational week, the patient underwent surgical termination of the pregnancy due to uncontrolled hypertension, with delivery of a viable fetus. The BP of the patient fluctuated between 140 and $177 / 90$ and $115 \mathrm{mmHg}$ subsequent to the termination of the pregnancy. An abdominal magnetic resonance imaging (MRI) scan and an ultrasound were performed 1 month subsequent to the termination of the pregnancy.

The MRI was performed and showed an oval-shaped mass on the right adrenal gland, as exhibited in Fig. 1. The mass was 

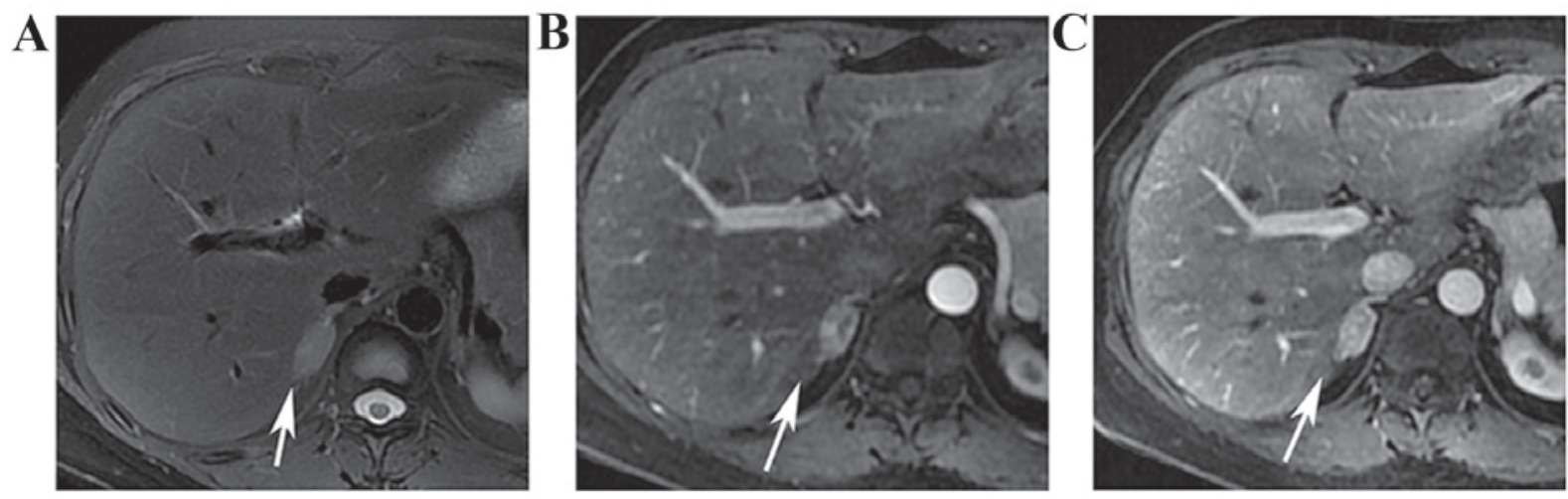

Figure 1. Axial T2-weighted-image of a magnetic resonance imaging scan. (A) axial multiphase dynamic contrast-enhanced (B) arterial phase (C) venous phase. Arrows highlight an oval-shaped mass on the right adrenal gland. The mass is hyperintensity on the T2 weighted-image, and shows heterogeneous enhancement during the arterial phase and the homogeneous enhancement during venous phase.

recorded as a hyperintensity region on the $\mathrm{T} 2$ weighted-image (T2WI), and showed a marked heterogeneous enhancement during the arterial phase and a homogeneous enhancement during the venous phase, which was considered typical of an adrenal adenoma. In addition, a small well-defined solid mass was found on the left kidney, which is demonstrated in Fig. 2. The lesion was recorded as isointense on the T1 weighted-image (T1WI) with a spot hyperintensity area, and was hyperintense on T2WI. The mass was not markedly enhanced during the arterial phase, and was slightly enhanced during the venous phase. The mass was observed to be isointense during the delay phase.

An ultrasound scan detected a clear hypoechoic mass on the right adrenal gland. However, a diagnosis of the lesion on the left kidney was not reached. The clinical diagnosis was functional adrenocortical adenoma, primary aldosteronism (PA), and a potentially malignant left renal tumor. The surgical team removed the right adrenal neoplasm first, and removed the left renal tumor subsequent to two months. The patient underwent a laparoscopic right adrenalectomy to remove the right adrenal neoplasm. Pathological analysis revealed that the neoplasm was an adrenocortical adenoma. However, the BP levels of the patient did not return to normal subsequent to the operation.

A total of 2 months later, a follow-up computed tomography (CT) angiography scan revealed normal renal arteries, but confirmed the presence of a $2.2-\mathrm{cm}$ mass in the left kidney, as exhibited in Fig. 3. The mass showed no marked enhancement during the arterial phase, and a slight enhancement during the portal venous phase. There was no change in the size of the lesion. The patient underwent a laparoscopic left partial nephrectomy to remove the lesion on the left kidney. The surgical procedure was successful, with no intraoperative or postoperative complications. The BP of the patient showed a substantial reduction from $177 / 115$ to $125 / 80 \mathrm{mmHg}$ on the day subsequent to surgery, and stabilized to be within the normal range. As a result, all antihypertensive therapies were discontinued 1 week later. The BP of the patient remained in the normal range subsequent to a 6-month follow-up.

Gross examination of the left partial nephrectomy sample showed a solitary, well-circumscribed tumor measuring
$2 \mathrm{~cm}$, with a grey-white colored section and some areas of hemorrhage, as demonstrated in Fig. 4A. The histological analysis revealed that the tumor cells were arranged solidly, or as amorphous plaques, exhibiting clear borderlines with the renal cortex (Fig. 4B). The tumor was composed of round and polygonal cells with eosinophilic cytoplasm, and regular cell nuclei and perinuclear halos were observed (Fig. 4C). During immunohistochemical analysis, the round uniform cells were stained and produced a strong positive result for the presence of the vascular marker cluster of differentiation (CD)34 (Fig. 4D), and a negative result for the presence of keratin AE1 andAE3, smooth muscle actin, chromogranin A, Syn, RCC, HMB45, S100, CD31 and Ki-67 markers. In conjunction with the clinical history, the histological findings and immunohistochemical analysis supported a diagnosis of reninoma.

\section{Discussion}

Reninoma is a benign neoplasm that produces renin and results in secondary hypertension with hyperaldosteronism and hypokalemia. Occasionally, the tumors exhibit malignant behavior (6-9). The incidence of reninoma is low: Since the first description in 1967 by Robertson et al (10), 100 cases have been reported, the majority of which occur in young adult females with a mean age of 27 years (11).

Among the number of reninoma cases reported (12-17), the patient of the present study case is the 7th study reporting a patient with reninoma during pregnancy. According to previous studies, the majority of reninomas present in the form of solitary tumor $(11,18)$. The coexistence of reninoma and bilateral pheochromocytoma has been previously reported (19), whereas the present study is the first case report of reninoma coexisting with an adrenal adenoma.

There are many data suggesting that secondary hypertension may be caused by several conditions, affecting the kidneys, heart, arteries or endocrine system. Common causes include renovascular hypertension, PA and pheochromocytoma (20). $\mathrm{PA}$ is considered to be the major common cause of secondary hypertension (21), which results from the inappropriate endogenous production of the mineralocorticoid aldosterone by the adrenal glands. The condition is also caused by 

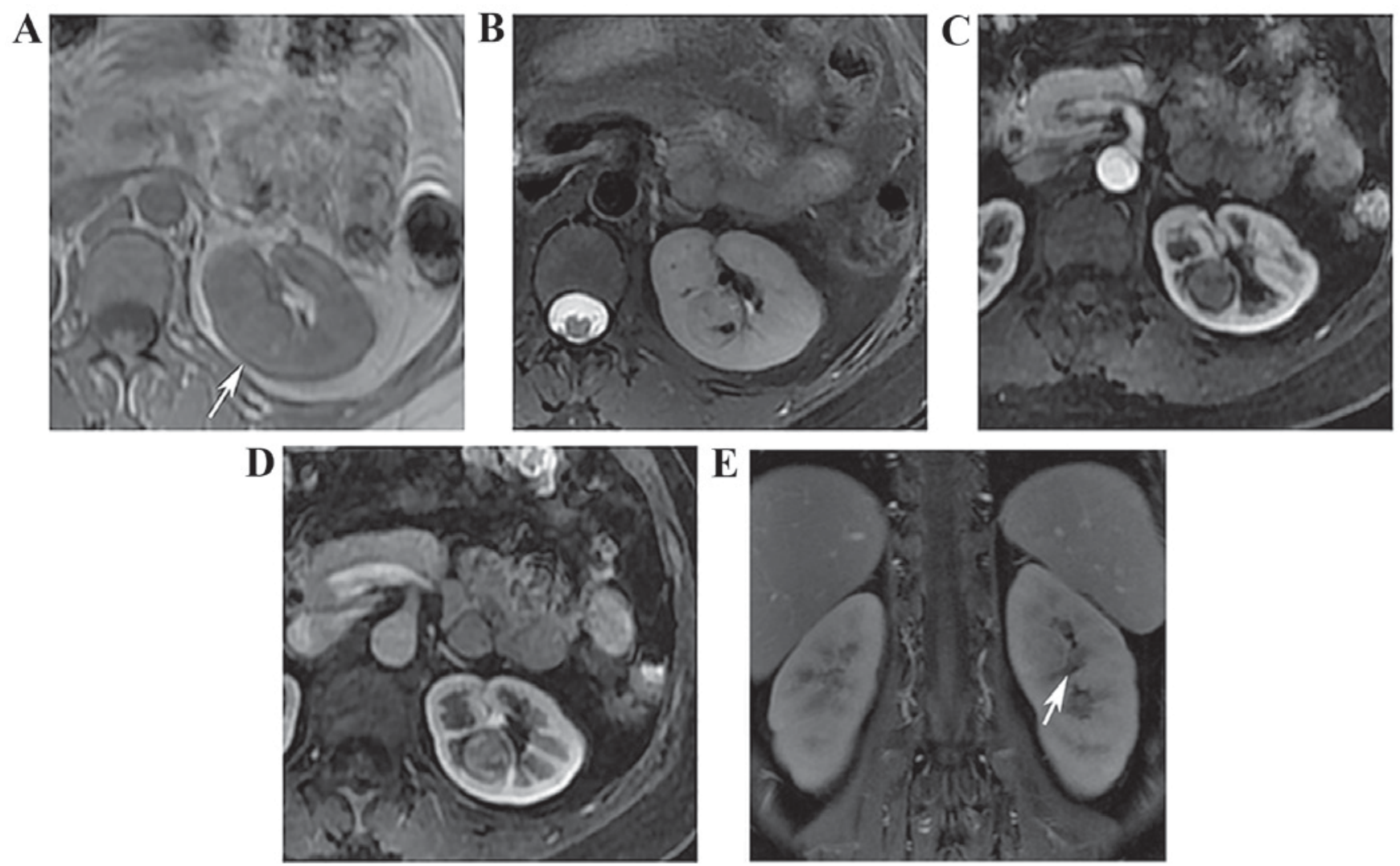

Figure 2. Axial T1WI. (A) Axial T2WI; (B) Axial multiphase dynamic contrast-enhanced [(C) arterial phase; (D) venous phase] and (E) coronal delay phase. Magnetic resonance imaging scan images show a round, well-defined solid mass on the left kidney. The mass is almost equi-signal on the T1WI with a spot hyperintensity area as denoted by the arrow (A), which confirmed hemorrhage. The tumor is slightly hyperintensive on T2WI, with a hypointensity-coated structure. The mass is not markedly enhanced during the arterial phase, and is slightly enhanced during the venous phase, becoming equi-signal during the delay phase, as denoted by the arrow (E). T1WI, axial T1 weighted-image; T2WI, axial T2 weighted-image.
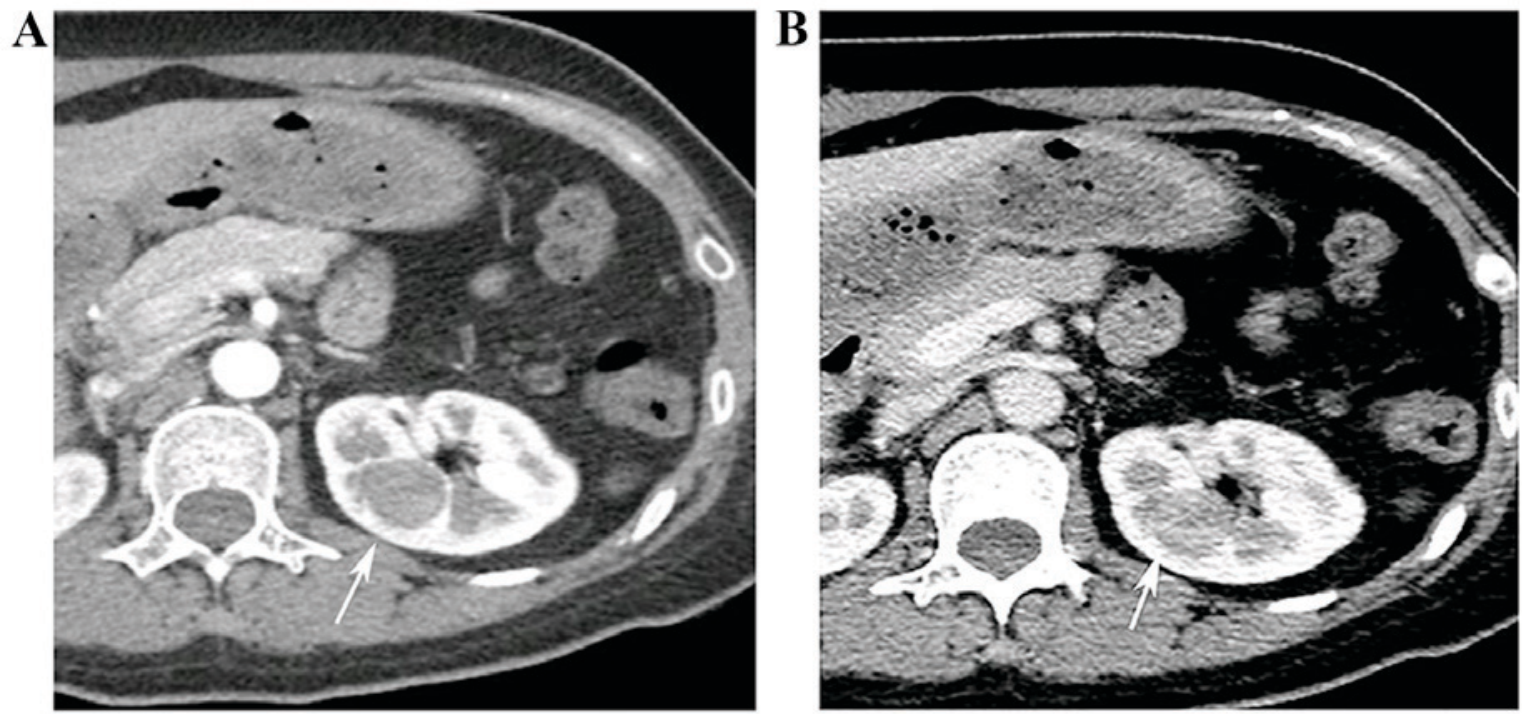

Figure 3. Axial enhanced computed tomography images. (A) Arterial phase. (B) Venous phase. Images show a small, well-defined solid mass on the left kidney. The mass is not markedly enhanced during the arterial phase, and is slightly enhanced during the venous phase.

solitary or multifocal aldosterone-producing adenomas, or less commonly by adrenal gland hyperplasias (22). As the patient in the present study exhibited neoplasms in the right adrenal gland and in the left kidney, the hypertension was presumed a result of PA, which was incorrect.
It is difficult to accurately diagnose the pathogeny of hypertension based solely on radiology imaging; lab examination is effective in achieving a correct diagnosis. Reninoma and PA are associated with hypokalemia, hyperaldosteronism and hypertension. Reninoma produce excessive amounts of 
A

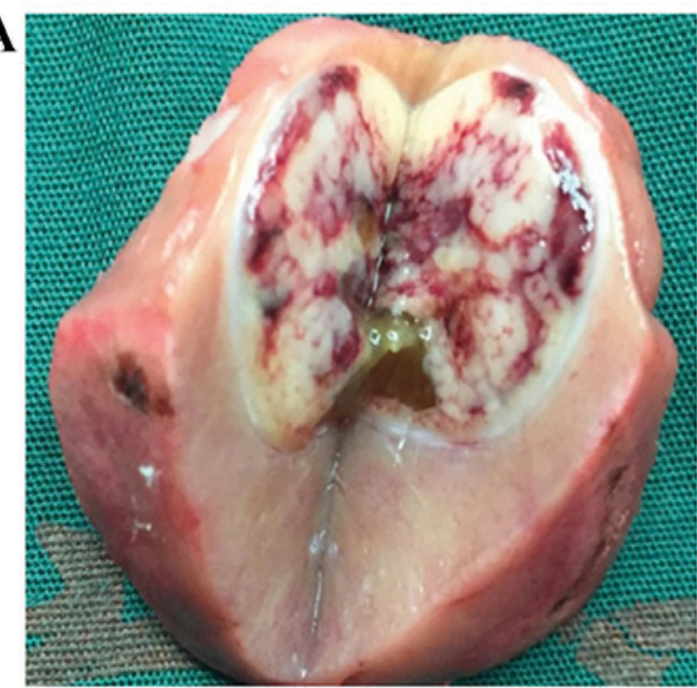

C

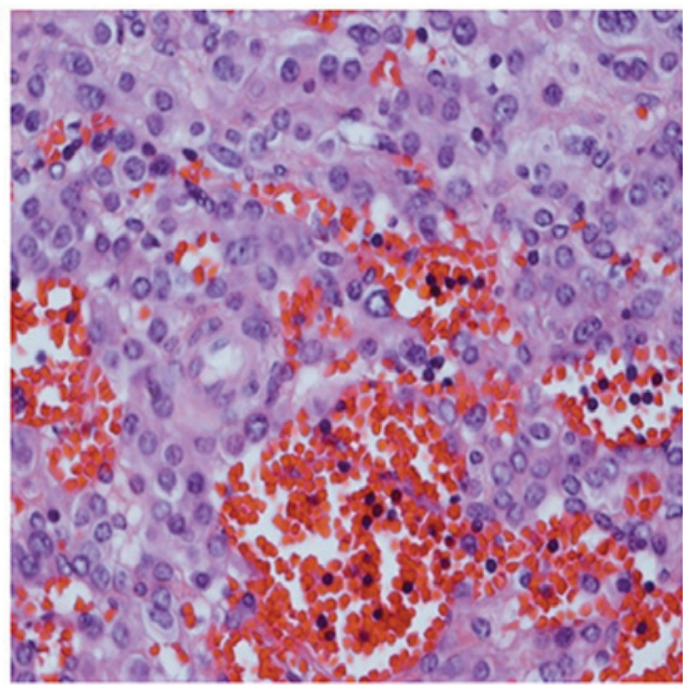

B

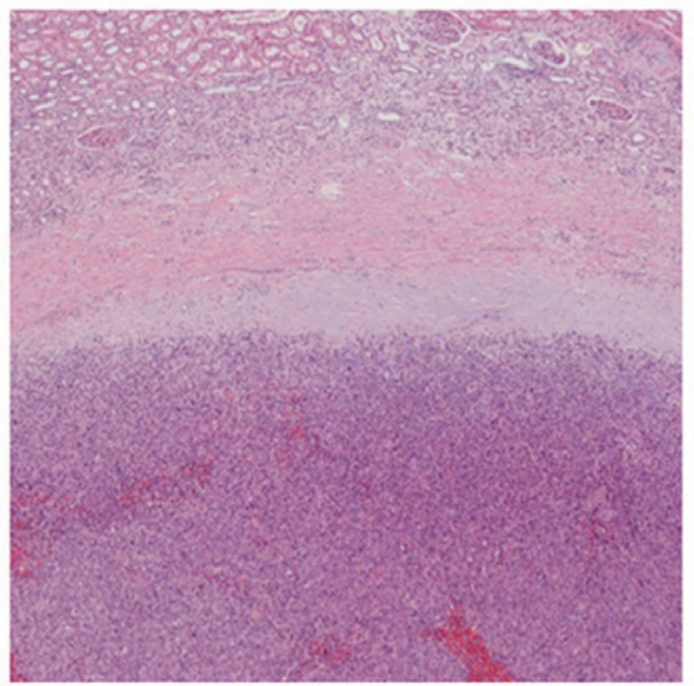

D

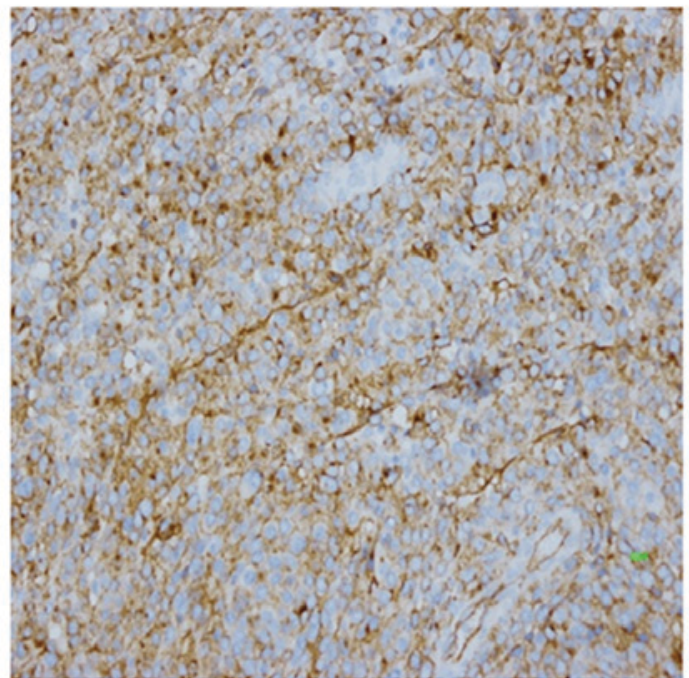

Figure 4. (A) Gross examination shows a solitary, well-circumscribed tumor with a mostly grey-white colored section and some areas of hemorrhage. (B) The tumor cells are arranged solidly or as amorphous plaque, and exhibit a relatively clear borderline with the renal cortex (magnification, $\mathrm{x} 100)$. (C) The tumor was composed of round and polygonal cells with eosinophilic cytoplasm. Regular cell nuclei and perinuclear halos may be observed. The tumor is rich in blood vessels (magnification, x400). (D) Immunohistochemical staining reveals that the tumor cells are immunohistochemically positive for the vascular marker cluster of differentiation 34 (magnification, x200).

renin, which results in secondary hyperaldosteronism, with the plasma renin levels remaining normal in PA patients (23). The level of hypertension of the patient was mistakenly linked to the right adrenal tumor when the patient was referred to the Chinese Academy of Medical Sciences Cancer Institute and Hospital (Beijing, China) prior to testing the level of renin. Retrospective analyses of the medical examinations of the patient were carried out by the Beijing Shijitan Hospital (Beijing, China), where the patient gave birth, and demonstrated that the renin level of the patient of the present study was clearly higher than the normal range, which provides additional evidence to support the hypothesis that the neoplasm in the left kidney of this patient was a reninoma. The laboratory examinations demonstrated hypokalemia, with levels of serum potassium measuring $3.48 \mathrm{mmol} / \mathrm{l}$, whereas the normal range is $3.5-5.3 \mathrm{mmol} / 1$. Plasma renin, angiotensin II and aldosterone levels were elevated in the supine and upright positions (renin: 19.40 and $24.30 \mathrm{ng} / \mathrm{ml} / \mathrm{h}$; angiotensin II: 370.20 and $425.30 \mathrm{pg} / \mathrm{ml}$; aldosterone: 19.22 and $27.18 \mathrm{ng} / \mathrm{dl}$ ), demonstrating that laboratory tests are useful for differential diagnosis.

Reninomas are difficult to identify with ultrasound technology, even in cases of known renal lesion. Therefore, if a reninoma is suspected, particularly in females with severe hypertension, CT or MRI scans may be considered as the primary diagnostic tool for screening renal tumors, in comparison with ultrasound scans. Small isodense lesions may not be detected by unenhanced CT scans: Therefore, enhanced CT scans may be performed for all suspected cases (18). Rosei et al (24) reported that CT scans are particularly sensitive at detecting this kind of tumor compared with MRI scans, as MRI scans may produce misleading results.

The radiological features of reninoma have been documented, presenting as hypo- or isodense solid masses with well-defined borders on an unenhanced CT scan, and remaining hypovascular on arterial phase images due to the vasoconstriction caused by the renin excreted from the tumor. Results from the MRI T1-weighted images demonstrate 
tumors in iso- or hypointense areas, whilst on the T2-weighted images they appear as hyperintense (25).

In conclusion, the present study described a rare case of reninoma coexisting with an adrenal adenoma during pregnancy. Reninoma should be included in the differential diagnoses of incidences of solitary regular renal masses with a slight enhancement in patients with hypertension, particularly in young females. Enhanced CT and MRI scans should be performed when reninoma is suspected. In addition, laboratory tests are highly recommended in differentiating reninoma.

\section{References}

1. Corvol P, Pinet F, Plouin PF, Bruneval P and Menard J: Renin-secreting tumors. Endocrinol Metab Clin North Am 23: 255-270, 1994.

2. Dong D, Li H, Yan W, Xu W, Lu L and Zeng Z: The diagnosis and surgical anagement of juxtaglomerular cell tumor of the kidney. J Hypertens 28: 628-632, 2010.

3. Szejnfeld D, Nunes TF, Giordano EE, Freire F, Ajzen SA, Kater CE and Goldman SM: Radiofrequency ablation of functioning adrenal adenomas: Preliminary clinical and laboratory findings. J Vasc Interv Radiol 26: 1459-1464, 2015.

4. Rayner B: Primary aldosteronism and aldosterone-associated hypertension. J Clin Pathol 61: 825-831, 2008.

5. Rossi GP, Bernini G, Caliumi C, Desideri G, Fabris B, Ferri C, Ganzaroli C, Giacchetti G, Letizia C, Maccario M, et al: A Prospective study of the prevalence of primary aldosteronism in 1,125 hypertensive patients. J Am Coll Cardiol 48: 2293-2300, 2006.

6. Shera AH, Baba AA, Bakshi IH and Lone IA: Recurrent malignant juxtaglomerular cell tumor: A rare cause of malignan hypertension in a child. J Indian Assoc Pediatr Surg 16: 152-154, 2011.

7. Duan X, Bruneval P, Hammadeh R, Fresco R, Eble JN, Clark JI, Vigneswaran WT, Flanigan RC and Picken MM: Metastatic juxtaglomerular cell tumor in a 52-year-old man. Am J Surg Pathol 28: 1098-1102, 2004.

8. Beaudoin J, Périgny M, Têtu B and Lebel M: A patient with a juxtaglomerular cell tumor with histological vascular invasion. Nat Clin Pract Nephrol 4: 458-462, 2008.

9. Dong D, Li H, Yan W and Xu W: Juxtaglomerular cell tumor of the kidney-a new classification scheme. Urol Oncol 28: 34-38, 2010.

10. Robertson PW, Klidjian A, Harding LK, Walters G, Lee MR and Robb-Smith AH: Hypertension due to a renin-secreting renal tumour. Am J Med 43: 963-976, 1967.
11. Wong L, Hsu TH, Perlroth MG, Hofmann LV, Haynes CM and Katznelson L: Reninoma: Case report and literature review. J Hypertens 26: 368-373, 2008.

12. Henderson NL and Mason RC: Juxtaglomerular cell tumor in pregnancy. Obstet Gynecol 98: 943-945, 2001.

13. Kim HJ, Kim CH, Choi YJ, Ayala AG, Amirikachi M and Ro JY: Juxtaglomerular cell tumor of kidney with CD34 and CD117 immunoreactivity: Report of 5 cases. Arch Pathol Lab Med 130: 707-711, 2006.

14. Lachvac L, Svajdler M, Valansky L, Nagy V, Benicky M, Frohlichova L and Nyitrayova O: Juxtaglomerular cell tumor, causing fetal demise. Int Urol Nephrol 43: 365-370, 2011.

15. Shin YS, Cha JS, Kang MJ, Park JK, Kim HJ and Kim MK: Newly developed hypertension due to juxtaglomerular cell tumor in pregnancy. Clin Nephrol 78: 325-327, 2012.

16. Ohashi Y, Kobayashi S, Arai T, Nemoto T, Aoki C, Nagata M and Sakai K: Focal segmental glomerulosclerosis secondary to juxtaglomerular cell tumor during pregnancy: A case report. Case Rep Nephrol Urol 4: 88-94, 2014.

17. Diker-Cohen T, Abraham SB, Rauschecker M, Papadakis GZ, Munir KM, Brown E, Lyssikatos C, Belyavskaya E, Merino M and Stratakis CA: Reninoma presenting in pregnancy. J Clin Endocrinol Metab 99: 2625-2626, 2014.

18. Gottardo F, Cesari M, Morra A, Gardiman M, Fassina A and Dal Bianco M: A kidney tumor in an adolescent with severe hypertension and hypokalemia: An uncommon case-case report and review of the literature on reninoma. Urol Int 85: 121-124, 2010.

19. Paragliola RM, Capoluongo E, Torino F, Minucci A, Canu G, Prete A, Pontecorvi A and Corsello SM: A rare case of juvenile hypertension: Coexistence of type 2 multiple endocrine neoplasia-related bilateral pheochromocytoma and reninoma in a young patient with ACE gene polymorphism. BMC Endocr Disord 15: 30, 2015.

20. Baglivo HP and Sánchez RA: Secondary arterial hypertension: Improvements in diagnosis and management in the last 10 years. Am J Ther 18: 403-415, 2011.

21. Young WF: Primary aldosteronism: Renaissance of a syndrome. Clin Endocrinol (Oxf) 66: 607-618, 2007.

22. Layden BT, Hahr AJ and Elaraj DM: Primary hyperaldosteronism: Challenges in subtype classification. BMC Res Notes 5: 602, 2012.

23. Kim SH, Ahn JH, Hong HC, Choi HY, Kim YJ, Kim NH, Yoo HJ, Kim HY, Seo JA, Kim NH, et al: Changes in the clinical manifestations of primary aldosteronism. Korean J Intern Med 29: 217-225, 2014.

24. Rosei CA, Giacomelli L, Salvetti M, Paini A, Corbellini C, Tiberio G and Muiesan ML: Advantages of renin inhibition in a patient with reninoma. Int J Cardiol 187: 240-242, 2015.

25. Karaosmanoğlu AD, Onur MR, Shirkhoda A, Ozmen M and Hahn PF: Unusual benign solid neoplasms of the kidney: Cross-sectional imaging findings. Diagn Interv Radiol 21: 376-381, 2015. 